\title{
Stigma and disaster risk reduction among vulnerable groups: Considering people receiving opioid substitution treatment
}

\author{
Denise Blake ${ }^{\mathrm{a}, *}$, Sheridan Pooley ${ }^{\mathrm{b}}$, Antonia Lyons ${ }^{\mathrm{c}}$ \\ ${ }^{a}$ Joint Centre for Disaster Research, School of Psychology, Massey University, Wellington, 6140, Aotearoa, New Zealand \\ ${ }^{\mathrm{b}}$ Community Alcohol \& Drug Services Auckland, Aotearoa, New Zealand \\ c School of Health, Victoria University, Wellington, 6140, Aotearoa, New Zealand
}

\section{A R T I C L E I N F O}

\section{Keywords:}

Stigma

Opioid substitution treatment

OST

Vulnerability

Disaster

Risk reduction

Preparedness

\begin{abstract}
A B S T R A C T
This work explores the ways in which stigma influences how people engage with disaster risk reduction. It specifically addresses the experiences and perceptions of stigma for people who receive Opioid Substitution Treatment (OST), a successful harm reduction strategy that reduces illicit drug use, risk of overdose and criminal activity. Unfortunately, while receiving OST people endure stigma because of their perceived or assumed history of drug use, which positions them as socially deviant and unacceptable. During a disaster or emergency, forms of social stigma from health and emergency management personnel have implications for access to treatment such as OST. Drawing on semi-structured interviews with 21 people receiving OST from services in four major cities in Aotearoa New Zealand, an interpretive analysis was applied to better understand how stigma matters to their lived experience. Four key themes, namely "Experiences of stigma", "Discrimination from health professionals", and "Disasters and emergency management" and "Support within disaster contexts" were identified in their talk. We conclude that it is vital that medications and other necessary treatments are made accessible to those who need them to maintain health and wellbeing. It is important to be aware that stigmatising beliefs manifest in disaster-response settings which have consequences for people who are already more vulnerable than others. Therefore we suggest that appropriate education and training be provided.
\end{abstract}

\section{Introduction}

People receiving opioid substitution treatment (OST) have specific needs that require a response during emergency planning or a disaster event, including access to medication. This group also experience social stigma which reflects the way in which healthcare workers and other professionals engage and interact with them, including people working in emergency management. This paper presents a research study that explored the perceptions and experiences of stigma among people receiving OST, particularly within a disaster setting where stigma may act as a barrier to engagement with emergency management practices and services. As background to this study, firstly we describe OST and discuss the concept of stigma both generally and also within a disaster context.

OST is a pharmaceutical and psychosocial harm reduction strategy that mitigates the chronic and relapsing pattern of problematic illicit opioid use [1]. In Aotearoa New Zealand OST includes methadone and buprenorphine/naloxone which are mostly consumed orally each day.
Both medications produce opioid effects; however methadone is a full agonist with a longer half-life while buprenorphine is partial and has a ceiling effect meaning the drug produces no more effect after a certain dose. Methadone is therefore much more likely than buprenorphine to cause overdose. People become physically dependent on both methadone and buprenorphine and will experience withdrawal symptoms in varying degrees if the medication is abruptly stopped. Classified under the Misuse of Drugs Act 1975, these medications are strictly regulated $[1,2]$ leading to people receiving OST having little agency over prescribing and consuming regimes. For instance, when new to treatment or assessed as clinically unstable, people are required to consume daily at an approved pharmacy. When judged eligible by health authorities, doses can be taken away and consumed elsewhere [1]. Without an OST dose, as with any long-term opioid use, withdrawal symptoms are experienced and can include nausea, diarrhoea, aching muscles, vomiting, anxiety, agitation and obsessive and reoccurring thoughts about the drug $[3,4]$. Unsurprisingly, withdrawals can lead to the use of illegal street drugs, discontinuation of treatment, and increases in injection

\footnotetext{
* Corresponding author.

E-mail address: d.blake@massey.ac.nz (D. Blake).
} 
practices which carry health risks [5,6].

Illicit drug use, or medically sanctioned drug use arising from illicit drug use, has long been subject to moral judgement. It discredits and taints people, positioning them as weak, sinful, dishonest and cunning [7]. Such stigma is greater when people are considered 'responsible' for a 'condition' that arises from their mind rather than their body [8]. Stigma affects people's attitudes and behaviours towards those with an identified or assumed history of drug use, classifying people who use drugs outside of socially acceptable 'norms'. Those receiving OST treatment experience the same public censure as heroin users $[9,10]$.

Link and Phelan [11], drawing on Goffman's work, describe the five mechanisms that produce stigma. Firstly, people are positioned as different based on undesirable social attributes, like drug use. Secondly, people are stereotyped based on those perceived differences, which then fosters intolerance and negative bias. Thirdly, labelling and categorising people as 'other' separates them from the group enacting the stigmata. Fourthly, discriminatory thoughts and actions can remove the social and political status of those in stigmatised groups; they become judged, marginalised and devalued based on allegedly justified rationales. Lastly, those stigmatised can find it difficult to socially, culturally and politically challenge the situation from an 'inferior' position, and can become frustrated with how they are treated. These five mechanisms are not necessarily linear, but collectively contribute to processes and experiences of stigma. Stigma is also 'felt' where there is fear of discrimination. People protect themselves from perceived stigma by hiding their 'condition' or avoiding exposure to potential stigmatising or discriminatory behaviour. Discrimination is the non-acceptance of particular people based on their perceived non-normative condition [12], which can be psychologically, socially and politically destructive [13].

Worldwide, research has demonstrated that people receiving treatment for opioid problems experience stigma in healthcare settings, which has effects on treatment processes $[9,14]$. For instance, In Connecticut, USA, Earnshaw, Smith, and Copenhaver [15] found that people receiving OST were generally perceived as subordinate and untrusting by family, friends, colleagues, employees, and healthcare workers because it was assumed that they would steal, or were drug seeking when requesting pain relief for legitimate reasons such as recovering from surgery. Similar to Earnshaw et al. [15], Conner and Rosen [9] found that older adults receiving methadone maintenance treatment in Midwestern, USA, experienced stigma in eight aspects of their lives (drug addiction, being on methadone and psychotropic medications, depression, age, socioeconomic position, ethnicity and HIV status) and felt disliked and judged by healthcare workers. In Ireland, Harris and McElrath [16] examined the experiences of people on methadone maintenance programmes and found that social control and institutional stigma reinforced the 'tainted identity' of the those positioned as 'drug addicts'. The general public assumed people who use drugs were less deserving of assistance than other health consumers in healthcare settings. This was highlighted by Luty and colleagues (2010) who found that some community pharmacy managers in the UK refused to provide methadone medication because of stigmatising attitudes, while the public also had unfavourable views towards people receiving OST in pharmacy settings. In Scotland, Gidman and Coomber [17] identified public fear and stigmatising attitudes towards people accessing OST in community pharmacies, namely that the public was afraid of violence and blood-borne diseases, and believed people on OST looked, spoke and behaved in deviant ways. Tellingly, some of the participants not engaged in OST reported feeling fearful about being called into the back room of pharmacies because they were considered spaces for administering OST. In Aotearoa New Zealand Berry et al. [18] noted that people receiving OST struggle to overcome drug problems because of stigma and marginalisation when homeless, unemployed and without meaningful pastimes. Berry et al. encouraged health professionals to address negative attitudes and stereotyping of clients. The Aotearoa New Zealand Mental Health and Addiction Service Development Plan 2012-2017 [19] also contests attitudes and practices of stigma and discrimination, encouraging health professionals to unpack inherent and often unconscious discriminatory practices. While it is argued that health professionals should attend to negative stigmatising beliefs about people on OST, this argument is also highly relevant to emergency management personnel who should be aware of any stigmatising attitudes, practices and behaviour.

Emergency responders from all disciplines come into contact with people needing support, as disruptions to opiate supplies and OST services is common following a disaster [20-22]. For instance, during the 2003 Bam earthquake in Iran, health and emergency rescue teams were inundated with high numbers of opiate users seeking help in the first three days but access to opiates was denied. Health and social care became essential, and need to be appropriately considered in emergency management planning prior to a disaster [23]. Similarly Bloodworth, Kevorkian, Rumbaut, and Chiou-Tan [24] found that when people presented at the Houston Astrodome seeking OST medication after Hurricane Katrina, treatment was delayed due to concerns about safety and theft if opioids were kept on-site. When opioid scripts were provided, people were expected to source a pharmacy in a disaster devastated area while others were transported to opioid treatment and recovery services where medication was eventually organised. Where medical records had been destroyed, people were made to wait until their withdrawal symptoms were evident before being treated.

During Hurricane Sandy in 2012, services providing OST in New York were unable to open because of communication problems and an inability to verify OST dose amounts [6]. In the week following the hurricane only $30.1 \%$ of those on methadone maintenance therapy were able to access a takeaway dose from their programme or doctor, while $22.9 \%$ received insufficient dosing so had to resort to street drugs to manage withdrawal symptoms [25]. Following Hurricane Sandy, a Manhattan Veteran's methadone clinic closed for five months due to being unable to meet the strict dispensing regulations. According to Griffin et al. [20]; another clinic was accredited expeditiously however that was not ideal because people were still displaced.

In 2017, in the aftermath of Hurricane Harvey, media reports indicated that an evacuee housed at the San Antonio emergency shelter went into opioid withdrawal; although they were given food and bedding, they were not given medication. This was justified through policy and regulation constraints preventing methadone dispensing, although the Texas Department of State Health Services acknowledged the precarious predicament for people receiving methadone in disaster settings [26].

In Aotearoa New Zealand, following the 2011 Canterbury earthquake, health professionals reported that nobody went without a prescribed OST dose. This was an accomplishment, although as conveyed by Blake and Lyons [27], across the country government officials, health professionals, and emergency managers still considered service continuity, communication, dosing and record keeping, stock, transport issues and service accessibility to be potential problems during a disaster. Blake [28] further reported that people receiving OST in Aotearoa New Zealand remained concerned about the inability to access medications following a disaster because of the potential physical and emotional distress. Participants stated that they would do whatever necessary to manage their withdrawals including criminal offending.

As well as experiencing stigma people on OST are often economically and socially under-resourced. A plethora of research (for example see Ref. [29-34] attests that people who endure such vulnerabilities experience more harm in a disaster context. Mainly attributed to structural forces [35], the specificity of these vulnerabilities are often overlooked in disaster risk reduction practices [36]. For instance, people who experience stigma, social marginalisation, economic and social hardship are constrained in their ability to have preparedness items such as food, clothing and sanitation equipment. They often reside in disaster prone areas, have substandard housing, and limited social capital which is necessary for resourcing, coordination, information sharing and psychosocial wellness and rebuilding lives after a disaster [29,32,37,38]. Although people positioned as vulnerable may have the ability to cope in 
a disaster context, a lack of access to medications such as opioids increases susceptibility to and risk of harm (for example see Ref. [28,38, 39]. It is necessary to understand the lived experiences of people receiving OST and explore how stigma might act as a barrier to disaster reduction, readiness, response and recovery. The aims of this research were to explore experiences of stigma among people receiving OST and identify how stigma might act as a barrier when interacting with emergency management professionals. We also aimed to coalesce stigma knowledge with disaster management research.

\section{Method}

\subsection{Design}

This study forms part of a larger research project exploring the views of a number of different groups, including OST workers, health professionals, and emergency managers in Aotearoa New Zealand. This paper reports only on the results from the participants receiving OST in Aotearoa New Zealand. To gain in-depth insight into people's lived experiences, qualitative interviews were carried out with people receiving OST. The project had the support of a number of key OST stakeholders, such as OST consumer advisors and emergency managers.

\subsection{Participants}

The 21 OST participants in this study were from OST services in four major cities in Aotearoa New Zealand. A combination of people receiving methadone and buprenorphine were interviewed, with their length of time on OST ranging from one to 30 years. They were aged approximately between 25 and 60 years, and there were eight women and 13 men.

\subsection{Procedure}

Ethical approval was obtained by Massey University's Human Ethics Committee. Purposive sampling, including cold-calling and snowballing, was used to recruit people who were currently engaged with opioid treatment in Aotearoa New Zealand. Research information sheets were also given out at Needle Exchange Services. Participants contacted the lead researcher directly after either seeing the information sheet or being informed about the research. One-on-one, face-to-face interviews were semi-structured and covered topics including knowledge of emergency planning for OST dispensing, preparedness, withdrawals, experiences and perceptions of stigma, and important information for emergency management responders. Interviews ranged in length from 25 to $90 \mathrm{~min}$ and were recorded and transcribed verbatim. Transcribed texts were anonymised, with names and identifying information removed, and organised for readability, with superfluous words deleted (for instance, "erm", and "you know"). Participants were given the opportunity to review their transcripts, but all declined. Supermarket vouchers $(\$ 40.00)$ were given to participants to thank them for their time.

\subsection{Analysis}

This work focused on exploring how stigma is experienced as a barrier to engagement with emergency management among people receiving OST. Drawing from qualitative psychology that values alternative knowledge production we employed interpretive analysis to identify patterns across experiences, views and perceptions of stigma, OST and emergency management [40-42]. This involved an inductive identification of themes whereby transcripts were read and re-read. A broad range of interpretive themes were grouped into detailed narrative codes using NVivo 11 software, such as "OST service characteristics", "emergency management groups", "disaster risk reduction", access and takeaway doses", "drug withdrawals" and "being misunderstood". These codes were conceptually arranged into broader themes based on the relationships between the codes and the overall research aims. This process of refinement continued until four key themes were identified that represented much of the data and were relevant to the primary research questions.

\section{Results}

The analysis led to the identification of four major themes in the participants' narratives. The first theme captured participants' descriptions of their experiences of stigma generally and how these experiences enabled and constrained a sense of self in the social world. The second focused on experiences of stigma and discrimination from health professionals, while the third theme represents participants' views and perceptions about emergency management and disaster planning. The fourth theme highlighted participants' ideas about ways to support people receiving OST in a disaster context. Each topic is discussed in more detail below, using participant quotes to illustrate key findings.

\subsection{Experiences of stigma: "Looked at sideways"}

This first section represents participants' experiences of felt and enacted stigma as they navigate the everyday social world. Because stigma in a disaster context is under researched for people receiving OST it is necessary to consider how wider relationships of stigma might influence experiences in a disaster setting. Consistent with previous research, in this study people believed that stigma excluded them from participating in society. They described the way in which stigma, enacted as a form of 'othering', stemmed from a deeply ingrained social mistrust because of the taken-for-granted characterisation of the problematic 'drug addict'. For instance, Betty found that once her drug using history became known "people always kind of look at [her] a bit sideways" while Suzie and Joe reasoned that drug addiction is "thought of as self-inflicted" and therefore they are "just drug addicts at the end of the day, so no one really cares" or has "compassion" for them. As observed by Albrecht et al. [8] the impacts of stigma are greater when attributed to a personal fault which in turn positions people as deviant to the norm. To be marginalised because of a perceived inherent fault means that people avoid public situations that might be uncomfortable, or where they risk being judged and misunderstood. This could include community hubs following a disaster. A review of OST in Aotearoa New Zealand over the past 40 years found that stigma prevents people from accessing treatment, and still dissuades general practitioners from being willing to prescribe OST [14]. According to Suzie, "drug addicts are one of the last groups you can pick on" in that there is little social or political debate about the stigma associated with illicit drug use in Aotearoa New Zealand. Suzie's narrative signifies the lack of agency to contest marginalisation. Andrew also considered himself a member of the most "marginalised of groups", indicating the depth of the burden he experienced. Andrew narrated the way in which stigma can "accumulate and compound" into a form of felt stigma that is readily evoked:

That's what stigma is, internalised discrimination, that you hold inside you, and then the problem is that once you've got that inside you, you can become very sensitive, and it doesn't take much of a poke for that to be activated. (Andrew).

For Andrew, sensitivity to stigma meant he was easily provoked to anger. Sarah also communicated her frustration at the blatant disrespect she endured due to stigma. Sarah described knowing she is unwelcome in a shop, when made to wait a long time for service and being treated with "rude" and "dismissive" behaviour:

... every now and again you'll come across someone that's got, sort of an attitude and they ... really sort of let it be known that they'd really rather you weren't in their shop. And they're certainly going to 
make you wait as long as they possibly can and be pretty rude and dismissive toward you. (Sarah)

During the interview Sarah's frustration at the blatant disrespect was palpable. As Goffman [7] argued stigma affects social relationships and prohibits people from achieving authentic citizenship in the social world. Even participants who possessed a robust sense of a 'self' talked about being oppressed by stigma. For example, in the following quote Mike represented the burden of stigma:

It drags me down, it makes me feel like I'm less than ... like I'm negatively perceived. And people are looking at me thinking, "you're one of them. We need to stay away from you" ... as much as I have an intact sense of who I am, it still gets to me. (Mike)

Mike's narrative provided cues to how being "dragged down" and made to feel inferior caused emotional angst. Reflecting on theories around protective strategies, Barreto [43] discussed forms of coping and resistance to stigma like appraisal and interpretation. Mike went on to demonstrate such proactive strategies by deflecting discrimination and attributing negative judgement to people's ignorance:

I've got to a point where I can't let it bother me anymore ... gone are the days when [being treated with suspicion] bothers me, because it's their lack of education, not mine. (Mike)

Clearly discriminatory actions directed toward Mike bothered him; however he had found ways to take up a more empowered position. Other participants also found ways to resist social marginalisation. Zoe, for instance, protected herself by contesting her stigmatised identity as a "drug addict" and expressed a desire to be "seen as me" - it can be assumed that this authentic "me" should be afforded the same rights and privileges as everybody else. Martin wanted to be recognised as fluid and multiple, more than just a person who has taken illicit drugs:

But the reality is he's a person, he's a father, he's a husband, he's a son. (Martin)

Here Martin acknowledges the range of identities people have in their lives beyond one linked to previously taking illicit drugs, which seems to dominate other people's perspectives. People receiving OST are not homogenous. The people in this study viewed the public as adhering to a narrow and problematic characterisation of people who use illicit or medically approved opioids, and continue to enact stigmatisation because of preconceived assumptions about what constitutes 'acceptable' citizenship. Not isolated to the general public, stigma also permeates professional boundaries, and participants all described experiencing stigma in health settings. The next section unpacks interactions with health professionals with the aim of understanding how such experiences might transpire in interactions with emergency management professionals.

\subsection{Discrimination from health professionals: "You're faking it"}

Relationships between the participants and professionals were marred with experiences of stigma and discrimination. As evidenced in the literature review above, throughout the world health professionals can treat people using illicit, even medically sanctioned drugs, as lesser and distrusting (for example see Ref. [15,44]. Martin's narrative supported these claims as he had endured "more stigma and stereotyping from professionals than your average [person]". Discriminatory behaviour by healthcare workers was a "huge issue" according to Jason because it impacted on the quality and type of medical treatment he received:

... as soon as [providers] hear I'm on methadone it's like this brick wall goes up. And it becomes a barrier to maybe getting treatment as quickly, or even being treated as a normal person, like you're just put in this whole other category. (Jason)
That a "brick wall" might prevent timely treatment is concerning, as is substandard treatment that sees a patient suffer. Additionally, Jason was concerned about negligible and inappropriate pharmacological pain treatment because of suspicion about drug seeking behaviour or illegitimate pain:

When you go to the ED (Emergency Department), they tend to be really sceptical ... of methadone patients. Like ... you're faking your gallbladder playing up to get some more drugs or something like that when you know there's clearly legitimate issues going on which can be verified with scans or tests. (Jason).

It is likely that comparable encounters would transpire in a disaster context if someone receiving OST is harmed. As stated earlier, research after Hurricane Katrina found that people had to show signs of withdrawals before they were treated with OST. While on the one hand this can be commended as safe health practices, it can also be perceived as distrust towards the integrity of people receiving OST [24]. To allow personal even unconscious bias to influence treatment is unethical and contravenes the New Zealand Medical Association Code of Ethics [45] which clearly stipulates that treatment must not be discriminatory and must align with the Aotearoa New Zealand Human Rights Act. With felt and enacted experiences of stigma it is unsurprising that participants felt they had little agency over treatment and that power and control is held by service providers. Blair questioned if professionals are even cognisant of their behaviour:

You just wouldn't treat people like that with diabetes, is what I keep thinking ... I just don't know if people realise that, how much bias or prejudice they actually do have. Even from treatment professionals who have been doing this every day. (Blair).

Often people receiving or advocating for OST draw on a diabetes metaphor to argue for the ordinariness and health status of OST. Notably, however, stigma directed toward people on OST appears to come from people who understand this and are in the best position to provide support, such as health workers $[9,10,15]$ and potentially emergency management personnel. Without reflexive practice professionals can unconsciously enact discrimination and construct barriers to service access and responsiveness. Some participants reported only going to medical appointments when absolutely necessary. This apprehension to seek professional help in a non-disaster setting because of discrimination and stigma could also manifest in a disaster scenario, as outlined in the following section.

\subsection{Disasters and emergency management: "They can bloody wait"}

The participants were asked how they thought stigma might matter in a disaster situation. Many were concerned that emergency professionals would "not [be] very nice" (Alan) because "we're the scum of the earth" (Eve). Historical stigma becomes internalised and felt, so in this sense, people in this study believed they would be perceived in derogatory ways regardless of the context [9].

In the event of a disaster in Aotearoa New Zealand, people are encouraged to seek or offer support at the local Community Hubs (also known as Civil Defence Centres). These spaces enable communities to coordinate response and recovery efforts if infrastructure or communication networks are disrupted [46]. They are also spaces to access psychosocial support. For the participants in this study however, Community Hubs signified spaces of uncertainty, judgement and fear. For instance, Bob recounted how he did not think his partner would go to a Community Hub because she dreaded her OST status being revealed:

...my partner, she's deathly afraid of anyone ever finding out. Because she is in a well-paid job ... you'd be afraid that it would affect your position. Yeah, I've watched her for years ... being deathly afraid that people would find out. (Bob) 
To be "deathly afraid" of identification constitutes an extreme fear of losing employment and respect from colleagues for Bob's partner. This was so overwhelming that in the event of a disaster she would not go to seek help. Participants worried that people in positions of authority would reject them and dismiss any valid request for opioid medication and support. The following three excerpts demonstrate how the participants perceived others would view them if they sought help at a Community Hub or other emergency management location. They described being a burden, not being cared about and being a low priority:

... they might want to, say, get rid of you, you're inconvenient, you're shameful, or they judge you because you're not a productive member of society or whatever. You know, bugger off. (Helen)

I just don't think that, most [emergency] centres, they wouldn't want to help. Sorting out our medication would be like, so down the list, it's like, we'll be abandoned. (Blair)

... because the level of stigma associated with this particular population, some people would be thinking, they can bloody wait ... because they're less deserving, so they can bloody wait. (Rachel)

Each narrative here represents the belief that people will be socially "abandoned" due to a stigmatised medical need. Like the others, Rachel thought she would be perceived as less deserving and as such, would be socially excluded. Similarly, Joe assumed that opioid treatment would not be a priority in a disaster setting because there would be legitimately injured people. He prioritised the injured over himself:

You'd have people injured, so really, getting methadone for somebody, wouldn't be top priority. You couldn't expect it to be. You know, people are injured (Joe)

It is evident that people receiving OST expect poor treatment by people in command of Community Hubs or emergency management spaces, should they need assistance accessing OST. An absence of social capital (networks and resources) can make it more difficult to rebuild after an emergency or disaster and accentuates unequal social power relations [37]. Insecurity and uncertainty about being accepted or helped produces unnecessary vulnerability in an already chaotic and extraordinary setting. In her research on social vulnerability and post-disaster settings, Naser-Hall [32] argued that it is important to be aware that the exclusion of people who are socially vulnerable from emergency plans is reflective of their social exclusion more generally. An attitude shift is necessary.

\subsection{Support within disaster contexts: "Potential solutions surely aren't that hard"}

When asked how participants thought health professionals or emergency management personnel could better support them and others there were a range of responses. For Blair, solutions were not difficult, they simply involved having knowledge about OST and what treatment means for people who receive it or not:

The potential solutions surely aren't that hard, it's just people have to care enough to make sure that people have to understand ... the reality of what it is for clients to be on the programme, or what happens to clients if they get denied access. (Blair)

A key sentiment expressed in Blair's narrative is care. Health and emergency management personnel should "care enough" to put in the effort to gain knowledge about what opioid use and withdrawals entail. Likewise, Helen said appropriate training about OST or personal experience or knowledge of addiction would promote open-mindedness:

If they've [welfare centre staff post-disaster] had any training it would be wonderful, or whether they've had any personal experience ... they may be more open minded. People that have ... education, be it life education or training, there can be a lot of judgement there, or if there's ignorance you know, they're not necessarily going to attempt to help you. (Helen)

Helen recognised that "judgement" and "ignorance", key elements of stigma, can be overcome with knowledge. With such knowledge, people in her position might receive help. Betty suggested that emergency management personnel should focus on treating the condition, rather than the history leading to the condition. Betty stated:

The route in to how you get there (OST) actually isn't relevant and you shouldn't be basing what you do on that. It's what the person's suffering from now, they need help with that. How they got there at this point doesn't matter and you have no right to make a judgement on that anyway. [In a disaster setting] you're there to treat this condition. (Betty)

That people are in a precarious position and "suffering" without medication should be the priority. It was suggested that appropriate training would encompass teaching emergency responders that OST is like any other medical condition in that it is life sustaining:

... this is just like any other medication people require it to be stable. You wouldn't deny somebody who's on heart medication - oh no you can go without that today. You just wouldn't do that, and this is no different. (Betty)

Without an OST dose, health and wellbeing in an already chaotic and compromising environment can lessen people's ability to survive. Joe asserted he would be incapacitated to the point that he could not the leave the house without his OST, while Sarah profoundly described how access to OST would help her family and the wider community:

If it became hard to get food and that sort of thing, I'd be hard pressed to leave my house, even. You know, you're struggling to drive properly, yeah just basically, you know, your body just starts losing normal functions. (Joe)

People are ... in survival mode and some people are on a lot of methadone, and they would not be functioning very well if they didn't have their drugs and that's going to be problematic for the wellbeing of those that they're responsible for. If they've got kids, or family or neighbours that usually they'd be in a position to help, but if they're like throwing up in a toilet or curled up in bed [they are not able to help] (Sarah)

Sarah equated access to OST in a disaster to survival for the person receiving OST as well as the people they care for, such as children or wider community members. Without their OST medication people would be vomiting or unable to move due to withdrawal symptoms and therefore unable to care for others. Previous disaster research (for example $[37,47]$ attests to the importance of social support for survival.

This section outlined the value of emergency management personnel acquiring inclusive knowledge about OST, so that this mostly marginalised group of people can be helped and supported in the same way as others in the community. This is particularly important in the context of a wider society that is unsure whether people in these positions 'deserve' treatment in the first place $[17,48,49]$.

\section{Discussion and conclusion}

Everyday felt and lived experiences of stigma will likely affect how people act during and after an emergency or disaster event. Stigmatising beliefs about people receiving OST are prolific within societies, including within health and social services, and as such spill-over into disaster-response situations leading to negative consequences for people, many of whom are already more vulnerable than others in these situations. A social and political shift is necessary towards people 
receiving OST because stigma incites and compounds stress and suffering.

While professionals struggle to separate their personal values and beliefs or general stereotypes - which may include unconscious, unexamined, or implicit assumptions and ideas from their everyday workplace - people receiving OST will continue to endure unjust and unethical treatment. Thus, we recommend that people working in disaster risk reduction service reflect on and unpack any stigmatising attitudes toward OST and the people who engage in opioid use and treatment.

Additionally, to reduce the harm of stigma, a series of policy and practice amendments are necessary including appropriate training and development opportunities for emergency management personnel [50] that moves beyond the command and control model that dominates emergency management in Aotearoa New Zealand and globally [29,51]. A command and control paradigm serves the needs of the elite and overlooks cultural and community specificity.

We recommend future research that elucidates the ways in which emergency managers currently experience and regulate underlying bias or stigmatising attitudes towards marginalised groups. It would be prudent to know what protocols currently guide dispensing of, and access to, controlled medications. Asking emergency management personnel what additional training or resources they might need to better engage with diverse communities would also strengthen a community approach to response and recovery [52].

While chronic illnesses generally tend to be 'taken seriously' by society at large, value-judgements are often made in reference to people who are participating in government-provided (therefore legal and legitimate) health treatment programmes. To combat this, interagency collaboration between OST services and emergency management is important to ensure treatment continuation [52]. This in turn will diminish anxiety and fear of discrimination for people needing treatment. More inclusive collaboration with broader social service agencies and users would be beneficial, including community pharmacists who have a pivotal role in OST provision and who have demonstrated that they go beyond their core role in a disaster to ensure safety and medical care $[27,53]$. Drawing on participatory action approaches that are founded on community empowerment values may better serve and strengthen disaster risk reduction capacity. As well as contesting acts of stigma, other service continuity options need to be investigated and, if appropriate, implemented to ensure treatment continuation during a disaster. Ideally OST service providers and emergency personnel would have clear shared pathways and protocols. Current contact information for people receiving OST and health officials, as well as a phone tree support system, transport alternatives and disaster drills, would all be beneficial [52,54].

Stigma also intersects more broadly with other illnesses and medically managed conditions. For instance, people with impairments and specific equipment needs are not adequately accounted for in disaster planning [55-57]. Including vulnerable groups in planning, implementation, and in everyday emergency management operations minimises unnecessary harm and increases the ability to respond and recover. Disaster risk reduction requires implementation using a human rights and environmental framework to achieve the best outcomes [51, 58,59].

The Aotearoa New Zealand National Disaster Resilence Strategy [60] and the Sendai Framework for Disaster Risk management $[61,62]$ are two well referenced documents that explicitly recognise that disaster risk reduction practices should involve inclusive and non-discriminatory practices that support community resilience. In its guiding principle, the Sendai Framework argues for disaster risk managers to attend to, and understand, dimensions of vulnerability to strengthen response and resiliency for all. There is also a need to empower and support those disproportionately affected by disasters and enable psychosocial support and recovery to minimise injury and damage. This will require active engagement with services delivering OST and with people receiving treatment. It is necessary to understand OST as a valid and successful harm reduction strategy, entrusted with the same respect as other life sustaining treatment regimes. As much as is practical, emergency planning needs to be cognisant of and responsive to the specificity of the protocols surrounding OST provision and understand its importance to the health and wellbeing of our people and communities. It also needs to educate responders and health care professionals about the negative impacts of stigma and the serious consequences it can have in disaster contexts.

\section{Acknowledgements}

The authors would like to acknowledge Kalpana Jayanatha for her early work and important contributions to this research. We would also like to thank the Massey University Research Fund (1000018625) grant for their support to undertake this research.

\section{Appendix A. Supplementary data}

Supplementary data to this article can be found online at https://doi. org/10.1016/j.ijdrr.2020.101588.

\section{References}

[1] Ministry of Health, New Zealand Practice Guidelines for Opioid Substitution Treatment, 2014. https://www.health.govt.nz/system/files/documents/publicati ons/nz-practice-guidelines-opioid-substitution-treatment-apr14-v2.pdf.

[2] Ministry of health, New Zealand Clinical Guidelines for the Use of Buprenorphine (With or without Naloxone) in the Treatment of Opioid Dependence, 2014. Retrieved from Wellington, New Zealand, https://www.health.govt.nz/system/ files/documents/publications/nz-guidelines-buprenorphine-2010.pdf.

[3] American Psychiatric Association, Substance-related and Addictive Disorders, 2015. http://dsm.psychiatryonline.org/doi/full/10.1176/appi.books.97 80890425596.dsm16\#x29473.2850891.

[4] D.R. Wesson, W. Ling, The clinical opiate withdrawal scale (COWS), J. Psychoact. Drugs 35 (2) (2003) 253-259, https://doi.org/10.1080/ 02791072.2003.10400007.

[5] H. Matusow, E. Benoit, L. Elliott, E. Dunlap, A. Rosenblum, Challenges to Opioid Treatment Programs after Hurricane Sandy: Patient and Provider Perspectives on Preparation, Impact, and Recovery, Substance Use \& Misuse, 2017, pp. 1-14, https://doi.org/10.1080/10826084.2016.1267225. Epub ahead of print.

[6] B. McClure, S. Mendoza, L. Duncan, J. Rotrosen, H. Hansen, Effects of regulation on methadone and buprenorphine provision in the wake of Hurricane Sandy, J. Urban Health 91 (5) (2014) 999-1008, https://doi.org/10.1007/s11524-014-9904-5.

[7] E. Goffman, Stigma: Notes on the Management of Spoilt Identity, Penguin Books, London, England, 1968.

[8] G. Albrecht, V. Walker, J. Levy, Social distance from the stigmatized: a test of two theories, Soc. Sci. Med. 16 (1319-27) (1982).

[9] K.O. Conner, D. Rosen, "You're nothing but a junkie": multiple experiences of stigma in an aging methadone maintenance population, J. Soc. Work. Pract. Addict. 8 (2) (2008) 244-264, https://doi.org/10.1080/15332560802157065.

[10] S. Murphy, J. Irwin, "Living with the dirty secret": problems of disclosure for methadone maintenance clients, J. Psychoact. Drugs 24 (3) (2012) 257-264, https://doi.org/10.1080/02791072.1992.10471646.

[11] B.G. Link, J.C. Phelan, Stigma and its public health implications, Lancet 367 (2006) 528-529, https://doi.org/10.1016/S0140-6736(06)68184-1.

[12] G. Scambler, Stigma and disease: changing paradigms, Lancet 352 (9133) (1998) 1054-1055, https://doi.org/10.1016/S0140-6736(98)08068-4.

[13] M. Fine, Just Research in Contentious Times: Widening the Methodological Imagination, Teachers College Press, Columbia University, New York, NY, 2018.

[14] D. Deering, J.D. Sellman, S. Adamson, Opioid substitution treatment in New Zealand: a 40 year perspective, N. Z. Med. J. 127 (1397) (2014) 57-66. http:// www.scopus.com/inward/record.url? eid=2-s2.0-84906324577\&partnerID $=40$ \&md5=2da71e6534d6514479788a530efd912c.

[15] V. Earnshaw, L. Smith, M. Copenhaver, Drug addiction stigma in the context ofmethadone maintenance therapy: an investigation into understudied sources of stigma, Int. J. Ment. Health Addiction 11 (2013) 110-122, https://doi.org/ 10.1007/s11469-012-9402-5.

[16] J. Harris, K. McElrath, Methadone as social control: institutionalized stigma and the prospect of recovery, Qual. Health Res. 22 (6) (2012) 810-824, https://doi. org/10.1177/1049732311432718.

[17] W. Gidman, R. Coomber, Contested space in the pharmacy: public attitudes to pharmacy harm reduction services in the West of Scotland, Res. Soc. Adm. Pharm. 10 (3) (2014) 576-587, https://doi.org/10.1016/j.sapharm.2013.07.006.

[18] R. Berry, P. Townshend, S. Pooley, D. Deering, L. Nixon, K. Vince, National Opioid Substitution Treatment Providers Training Programme, Ministry of Health, Wellington, 2010.

[19] Ministry of Health, Rising to the Challenge: the Mental Health and Addiction Service Development Plan 2012-2017, 2012. Retrieved from Wellington: http: 
//www.health.govt.nz/publication/new-zealand-practice-guidelines-opioid-su bstitution-treatment-2014.

[20] A.R. Griffin, C. Der-Martirosian, A. Gable, T. Wyte-Lake, A. Dobalian, A crisis within a crisis: the extended closure of an opioid treatment program after Hurricane Sandy, J. Drug Issues 48 (4) (2018) 536-545, https://doi.org/10.1177 0022042618779541.

[21] J.C. Maxwell, D. Podus, D. Walsh, Lessons learned from the deadly sisters: drug and alcohol treatment disruption, and consequences from Hurricanes Katrina and Rita, Subst. Use Misuse 44 (2009) 1681-1694, https://doi.org/10.3109/ 10826080902962011.

[22] D. Snow, M. Gotcher, Mental health preparedness for trauma includes addiction and chronic pain, J. Addict. Nurs. 17 (2006) 1-3, https://doi.org/10.1080/ 10884600600599176.

[23] A.R. Movaghar, R.R. Goodarzi, E. Izadian, M.R. Mohammadi, M. Hosseini, M. Vazirian, The impact of bam earthquake on substance users in the first 2 weeks: a rapid assessment, J. Urban Health 82 (3) (2005) 370-377, https://doi.org/ 10.1093/jurban/jti089.

[24] D.M. Bloodworth, C.G. Kevorkian, E. Rumbaut, F.Y. Chiou-Tan, Impairment and disability in the astrodome after Hurricane Katrina: lessons learned about the needs of the disabled after large population movements, Am. J. Phys. Med. Rehabil. 86 (9) (2007) 770-775, https://doi.org/10.1097/PHM.0b013e31813e0439.

[25] E.R. Pouget, M. Sandoval, G.K. Nikolopulos, S.R. Friedman, Immediate impact of Hurricane Sandy on people who inject drugs in New York City, Subst. Use Misuse 50 (2015) 878-884, https://doi.org/10.3109/10826084.2015.978675.

[26] D.M. Davies, Hurricane Harvey: addicted and evacuated can be a harsh combination. KSTX - san Antonio BBC world service. http://tpr.org/post/hurricane -harvey-addicted-and-evacuated-can-be-harsh-combination, 2017, 30 August.

[27] D. Blake, A. Lyons, Opioid substitution treatment planning in a disaster context: perspectives from emergency management and health professionals in Aotearoa/ New Zealand, Int. J. Environ. Res. Publ. Health 13 (1122) (2016) 2-14, https://doi, org/10.3390/ijerph13111122.

[28] D. Blake, Access to healthcare: opioid substitution treatment following a disaster in Aotearoa New Zealand, Australian Commun. Psychol. 29 (1) (2018) 121-138.

[29] D. Blake, J. Marlowe, D. Johnston, Get prepared: discourse for the privileged? Int. J. Disaster Risk Reduct. (2017) 283-288, https://doi.org/10.1016/j. ijdrr.2017.09.012.

[30] B. Bolin, Race, class, ethnicity, and disaster vulnerability, in: H. Rodriguez, E. L. Quarantelli, R.R. Dynes (Eds.), Handbook of Disaster Research, Springer Science, New York, NY, 2007, pp. 113-129.

[31] S. Hoffman, Preparing for disaster: protecting the most vulnerable in emergencies, Univ. California Davis Law Rev. 42 (2009) 1491-1547. https://lawreview.law.ucd avis.edu/issues/42/5/articles/42-5_Hoffman.pdf.

[32] E. Naser-Hall, The disposable class: ensuring poverty consciousness in natural disaster preparedness, DePaul J. Soc. Justice 7 (1) (2013) 55-86.

[33] K. Tierney, The Social Roots of Risk: Producing Disasters, Promoting Resilence, Standford Uniersity Press, Standford, CA, 2014.

[34] M.J. Zakour, D.F. Gillespie, Community Disaster Vulnerability: Theory, Research, and Practice, Springer, New York, NY, 2013.

[35] R.C. Keller, Fatal Isolation: the Devastating Paris Heat Wave of 2003, University of Chicago Press, Chicago, IL, 2015.

[36] K. Tierney, Disasters: A Sociological Approach, Polity Books, Cambridge, UK, 2019.

[37] D.P. Aldrich, Building Resilience: Social Capital in Post-disaster Recovery, The University of Chicago Press, Chicago, Il, 2012.

[38] B. Wisner, P. Blaikie, T. Cannon, I. Davis, At Risk: Natural Hazards, People's Vulnerability and Disasters, Routledge, New York, NY, 2004.

[39] F. Luna, Elucidating the concept of vulnerability: layers not labels, Int. J. Feminist Approach. Bioethics 1 (2) (2009) 121-139.

[40] V. Braun, V. Clarke, Using thematic analysis in psychology, Qual. Res. Psychol. 3 (2) (2006) 77-101, https://doi.org/10.1191/1478088706qp063oa.

[41] B. Gough, A. Lyons, The future of qualitative research in psychology: accentuating the positive, Integr. Psychol. Behav. Sci. 50 (2016) 234-243, https://doi.org/ 10.1007/s12124-015-9320-8.

[42] C. Willig, Introducing Qualitative Research in Psychology, third ed., Open University Press, New York, NY, 2013.
[43] M. Barreto, Experiencing and coping with social stigma, in: J.F. Dovidio, M. Hewstone, P. Glick, V. Esses (Eds.), APA Handbook of Personality and Social Psychology vol. 2, American Psychological Association, Washington, DC, 2015, pp. 473-506. Group Processes.

[44] C.L. Barry, E.E. McGinty, B.A. Pescosolido, H.H. Goldman, Stigma, discrimination, treatment effectiveness, and policy: public views about drug addiction and mental illness, Psychiatr. Serv. 65 (10) (2014) 1269-1272.

[45] New Zealand Medical Assoication Code of Ethics, Code of Ethics. Aotearoa New Zealand, 2014 (Wellington).

[46] Wellington Regional Emergency Management Office, Community Emergency Hubs, 2018. https://www.getprepared.nz/my-community/community-emergen cy-hubs/.

[47] E. Klinenberg, Heat Wave: A Social Autopsy of Disaster in Chicago, second ed., University of Chicago Press, Chicago, 2015.

[48] J. Luty, P. Kumar, K. Stagias, Stigmatised attitudes in independent pharmacies associated with discrimination towards individuals with opioid dependence, The Psychiatrist 34 (2010) 511-514, https://doi.org/10.1192/pb.bp.109.028951.

[49] P. Radcliffe, A. Stevens, Are drug treatment services only for 'thieving junkie scumbags'? Drug users and the management of stigmatised identities, Soc. Sci. Med. 67 (7) (2008) 1065-1073, https://doi.org/10.1016/j. socscimed.2008.06.004.

[50] D. Blake, P. Niland, D. Johnston, "In case of an emergency - plan": Aotearoa New Zealand health emergency management personnel's talk about legislation and policy, J. Emerg. Manag. 17 (5) (2019) 359-369, 10.5055/jem.2019.0435.

[51] A.J. Imperiale, F. Vanclay, Command-and-control, emergency powers, and the failure to observe United Nations disaster management principles following the 2009 L'Aquila earthquake, Int. J. Disaster Risk Reduct. 36 (2019), https://doi.org/ 10.1016/j.ijdrr.2019.101099.

[52] L. Elliott, E. Benoit, H. Matusow, A. Rosenblum, Disaster preparedness among opioid treatment programs: policy recommendations from state opioid treatment authorities, Int. J. Disaster Risk Reduct. 23 (2017) 152-159, https://doi.org/ 10.1016/j.ijdrr.2017.05.001.

[53] D.A. Epp, Y. Tanno, A. Brown, B. Brown, Pharmacists' reactions to natural disasters, Can. Pharm. J. 149 (4) (2016) 204-215, https://doi.org/10.1177/ 1715163516652423.

[54] K. Horahan, H. Morchel, M. Raheem, L. Stevens, S. Pawlak, Electronic health records access during a disaster, Online J. Publ. Health Inf. 5 (3) (2014), https:// doi.org/10.5210/ojphi.v5i3.4826.

[55] A. Aitsi-Selmi, V. Murray, Protecting the health and well-being of populations from disasters: health and health care in the Sendai framework for disaster risk reduction 2015-2030, Prehospital Disaster Med. 31 (1) (2015) 74-78, https://doi. org/10.1017/S1049023X15005531.

[56] M.A. Jhung, N. Shehab, C. Rohr-Allegrini, D.A. Pollock, R S, F. Guerra, D. B. Jernigan, Chronic diseases and disasters: medication demands of hurricane Katrina evacuees, Am. J. Prev. Med. 33 (3) (2007) 207-210, https://doi.org/ 10.1016/j.ampere.2007.04.030.

[57] K. Mori, K. Ugai, Y. Nonami, T. Kirimura, C. Kondo, T. Nakamura, H. Kaji, Health needs of patients with chronic diseases who lived through the Great Hanshin earthquake, Disaster Manag. Response 5 (2007) 8-13, https://doi.org/10.1016/j. dmr.2006.11.002.

[58] United Nations, Sustainable Development Knowledge Platform: Sustainable Development Goals, 2017. https://sustainabledevelopment.un.org/sdgs.

[59] United Nations Office for Disaster Risk Reduction, Implementing the Sendai Framework to Achieve the Sustainable Development Goals, 2016. https://www.uni sdr.org/we/inform/publications/50438.

[60] Ministry of Civil Defence \& Emergency Management, National disaster resilience strategy. Rautaki A--Motu Manawaroa Aitua ${ }^{-}, 2019$ (Retrieved from Wellington New Zealand).

[61] A. Aitsi-Selmi, V. Murray, The Sendai framework: disaster risk reduction through a health lens, Bull. World Health Organ. 93 (6) (2015) 362, https://doi.org/ 10.2471/BLT.15.157362.

[62] United Nations, Sendai Framework for Disaster Risk Reduction 2015-2030. Sendai, Japan: United Nation's International Strategy for Disaster Reduction, 2015. 